\title{
Pathological buying symptoms are associated with distortions in judging elapsed time
}

\author{
JENNIFER NICOLAI ${ }^{1}$ and MORTEN MOSHAGEN ${ }^{2 *}$ \\ ${ }^{1}$ Department of Cognition and Individual Differences, University of Mannheim, Mannheim, Germany \\ ${ }^{2}$ Research Methods, Institute of Psychology and Education, Ulm University, Ulm, Germany
}

(Received: February 12, 2018; revised manuscript received: July 31, 2018; accepted: August 3, 2018)

\begin{abstract}
Background and aims: Pathological buying (PB) is often assumed to be related to deficits in impulse control. Distortions in judging elapsed time are one component of behavioral impulsivity. This study was set out to examine the hypothesis that PB propensity is associated with distorted time perception, such that time is perceived to pass more slowly. Methods: The study is based on a convenience sample of 78 adults. Symptom severity of PB and related problems/disorders (substance use, borderline, depression, mania, and obsessive-compulsive disorder) as well as four dimensions of trait impulsivity were assessed. A time-production task was employed that required participants to produce prespecified time intervals ranging from 1 to $60 \mathrm{~s}$. Results: PB propensity was associated with the belief that time elapses more slowly, even when controlling for symptoms of related disorders and general trait impulsivity. Neither trait impulsivity nor symptoms of related disorders were predictive of distortions in judging elapsed time. Discussion and conclusion: These results suggest that PB propensity is related with non-specific, general deficits in judging elapsed time as a specific component of behavioral impulsivity.
\end{abstract}

Keywords: pathological buying, compulsive buying, behavioral impulsivity, time perception

\section{INTRODUCTION}

Pathological buying (PB) is characterized by thoughts about buying and impulses to buy that are experienced as being difficult to resist (McElroy, Keck, Pope, Smith, \& Strakowski, 1994). Commonly applied diagnostic criteria include (a) a recurrent preoccupation with buying and/or irresistible urges to buy, (b) repetitive buying that is difficult to control (and does not exclusively occur during manic episodes), and (c) negative consequences such as distress and significant social and/or financial problems (Dittmar, 2004; McElroy et al., 1994; Müller, Mitchell, \& De Zwaan, 2015; Racine, Kahn, \& Hollander, 2014). According to a recent meta-analysis, $\mathrm{PB}$ is a highly prevalent disorder affecting about $5 \%$ of the general adult population (Maraz, Griffiths, \& Demetrovics, 2016). PB exhibits high comorbidities, including affective, anxiety, substance use, and obsessive-compulsive disorders (Christenson et al., 1994; Müller, Mitchell, et al., 2015; Schlosser, Black, Repertinger, \& Freet, 1994).

Despite its high prevalence and the potentially severe negative consequences, PB is not included in the American Psychiatric Association's Diagnostic and Statistical Manual of Mental Disorders. In the International Classification of Diseases, version 11, PB can be classified in the category "other specified impulse control disorders." Although the issue of how PB should be best classified is currently under debate, it is generally assumed that dysfunctions in impulse control represent core features of PB (Billieux, Rochat, Rebetez, \& Van der Linden, 2008; Black, Shaw, McCormick, Bayless, \& Allen, 2012; Zander, Claes, Voth, de Zwaan, \& Müller, 2016). Supporting this notion, PB has been repeatedly associated with elevated scores on questionnaire measures of dispositional impulsivity, in particular with the incapacity to suppress a dominant response under strong affect (urgency), the tendency to act without thinking (lack of premeditation), and the inability of staying focused on a task (lack of perseverance; Billieux et al., 2008; Black et al., 2012; Claes \& Müller, 2017; Lejoyeux, Tassain, \& Adès, 1997; Rose \& Segrist, 2014; Vogt, Hunger, Pietrowsky, \& Gerlach, 2015; Williams \& Grisham, 2012)

Importantly, however, research indicates that impulsivity must be considered as multifaceted construct that encompasses a multitude of different separate behavioral tendencies (Cyders \& Coskunpinar, 2011; Reynolds, Ortengren, Richards, \& de Wit, 2006; Sharma, Markon, \& Clark, 2014; Stahl et al., 2014). A crucial distinction is made between dispositional impulsivity (assessed through questionnaires) and behavioral impulsivity (as evident in the performance of cognitive tasks). Dispositional impulsivity taps stable traitlike dispositions in ways of perceiving the world and

* Corresponding author: Morten Moshagen; Research Methods, Institute of Psychology and Education, Ulm University, AlbertEinstein-Allee 47, 89081 Ulm, Germany; Phone/Fax: +49 78150 31850; E-mail: morten.moshagen@uni-ulm.de

This is an open-access article distributed under the terms of the Creative Commons Attribution-NonCommercial 4.0 International License, which permits unrestricted use, distribution, and reproduction in any medium for non-commercial purposes, provided the original author and source are credited, a link to the CC License is provided, and changes - if any - are indicated. 
responding to it, whereas behavioral impulsivity refers to more specific cognitive processes. Both dispositional and behavioral impulsivity, in turn, consist of different components that show little overlap, so that they must be considered separate and distinct constructs (Cyders, 2015; Sharma et al., 2014). Correspondingly, it is mandatory to delineate which components of behavioral impulsivity in particular are affected and how they are affected in order to advance our understanding of impulsivity in PB.

Models of behavioral impulsivity suggest that at least six different types of cognitive processes can be involved in impulse control (Cyders \& Coskunpinar, 2011; Stahl et al., 2014): (a) the abilities to suppress distracting stimuli in the environment (stimulus interference) or (b) conflicting representations in memory (proactive interference), (c) the ability to withhold dominate responses (response interference), (d) the decision about the amount of elaboration prior to making a decision (information sampling), (e) the ability to resist temptations and short-term rewards (delay discounting), and (f) the ability to accurately judge elapsed time (distortions in judging elapsed time). Existing evidence on specific components of behavioral impulsivity in PB indicates impairments in the ability to withhold or interrupt a dominant response (response inhibition; Derbyshire, Chamberlain, Odlaug, Schreiber, \& Grant, 2014; Hague, Kellett, \& Sheeran, 2016; Nicolai, Darancó, \& Moshagen, 2016) and more discounting of delayed rewards (Nicolai \& Moshagen, 2017). PB has also been associated with deficits in inhibiting environmental buying cues (Büttner et al., 2014; Starcke, Schlereth, Domass, Schöler, \& Brand, 2012; Trotzke, Starcke, Pedersen, \& Brand, 2014), which can be seen as an analogue to the ability to inhibit stimuli that distract from current goal pursuit (stimulus interference). Finally, several studies investigated performance on tasks (Game of Dice Task, Iowa Gambling Task, and the Cambridge Gambling Task) that involve decision-making under ambiguity and under risk, which is loosely related to decisional components of impulsivity in goal selection (information sampling). However, mixed results have been found for both decision-making under ambiguity (Black et al., 2012; Trotzke, Starcke, Pedersen, Müller, \& Brand, 2015; Voth et al., 2014) and decision-making under risk (Derbyshire et al., 2014; Trotzke et al., 2015). On the whole, research indicates that $\mathrm{PB}$ is associated with deficits in some, but not all components of behavioral impulsivity.

The ability to accurately judge elapsed time is a component of behavioral impulsivity that has not been studied in $\mathrm{PB}$, to date. Generally, cognitive models assume that an internal clock with a pacemaker produces subjective time units that form the basis to judge elapsed time (Wittmann \& Paulus, 2008; Zakay, 2014). As a higher speed of the pacemaker results in the accumulation of more subjective time units over time, individual differences in time perception result as a consequence of a different speed of the pacemaker with more impulsive individuals tending to believe that time passes more slowly (e.g., believe that 30 s have elapsed when factually only 20 s have passed; Lawrence \& Stanford, 1998). As such, the perception of elapsed time is a critical component for the subjective experience of boredom (Danckert \& Allman, 2005; Zakay, 2014), which, in turn, has been linked to psychological problems such as depression and anxiety
(Goldberg, Eastwood, LaGuardia, \& Danckert, 2011; Skodol et al., 2002; Sommers \& Vodanovich, 2000). Several studies have demonstrated a relationship between impulsivity and an altered sense of time (Barratt, 1983; Berlin \& Rolls, 2004; Lawrence \& Stanford, 1998; Moreira, Pinto, Almeida, \& Barbosa, 2016; Wittmann, Leland, Churan, \& Paulus, 2007; Wittmann et al., 2011) in that high-impulsive individuals have a faster cognitive tempo than low-impulsive individuals. Moreover, it has been argued that a faster cognitive tempo among highly impulsive individuals forms the basis for a variety of impulsive behaviors (Patton, Stanford, \& Barrett, 1995; Wittmann \& Paulus, 2008). For example, differences in the ability to resist temptations associated with short-term benefits that take precedence over larger, but delayed rewards (i.e., delay discounting) may at least partly explained by individual differences in time perception (Wittmann \& Paulus, 2008). To the extent that individuals perceive time to pass more slowly, the delay associated with a reward subjectively increases. Correspondingly, perceiving time to pass more slowly makes waiting for a reward more difficult and thus leads to a preference for smaller, immediate rewards.

Based on the above findings, there are various reasons to assume that $\mathrm{PB}$ is related to distortions in judging elapsed time. Generally, individuals with PB underestimate the time passed during buying episodes (McElroy et al., 1994), which might reflect non-specific deficits in judging elapsed time. In addition, individuals with PB use buying to alleviate feelings of boredom (Lejoyeux et al., 1997), which might indicate elevated boredom proneness as a consequence from a higher pace of the internal clock. Finally, PB propensity has been shown to be associated with a preference for immediate, but smaller rewards relative to delayed, but larger rewards (Nicolai \& Moshagen, 2017). The preference of smaller immediate rewards over larger delayed rewards is usually seen as an indication of impulsivity (Reynolds \& Schiffbauer, 2004). With respect to PB, the preference of smaller immediate rewards might thus be explained by the tendency to perceive time to pass more slowly, so that delays associated with a reward are subjectively perceived to be longer. In sum, there are various reasons to expect that PB symptoms may be associated with the belief that time passes more slowly in conditions without stimulation, that is, that individuals with $\mathrm{PB}$ are likely to show distortions in judging elapsed time in the sense that they believe that time passes more slowly.

Accordingly, the aim of this study was to explore the association between time perception and PB propensity. In addition, a self-report measure of dispositional impulsivity was included in order to disentangle dispositional and behavioral components of impulsivity. It was hypothesized that PB symptoms are associated with distortions in judging elapsed time, such that these individuals perceive time to pass more slowly, irrespectively of symptoms of related disorders and general trait impulsivity.

\section{METHODS}

\section{Participants}

Seventy-eight college students (60 females, 1 "prefer not to say") were recruited from a midsize German university. 
Mean age was 23.49 years $(S D=5.22)$. Participants completed the study on an anonymous and voluntary basis. Course credit was given for participation.

\section{Procedure}

In order to minimize participant burden and fatigue, the questionnaires and behavioral measure were collected on separate days. Participants completed the questionnaires using the Internet at their convenience outside of the laboratory and approximately 3 days $(M=2.6, S D=3.1)$ later a behavioral task assessing time perception in the laboratory. Self-report and behavioral data were assessed separately to avoid carryover (or related) effects. To control for order-effects and systematic response bias, the questionnaires were presented in random order. After completing the questionnaires, random, completely anonymous codes (IDs) were displayed and participants were asked to copy their IDs in order to enter them in the laboratory study.

\section{Measures}

Beyond a measure of PB and a behavioral measure of time distortion, this study also assessed various control variables, particularly the four dimensions of dispositional impulsivity according to the UPPS model and a set of potentially relevant clinical background variables, including symptom severity measures of mental disorders that are known to be related to $\mathrm{PB}$.

Time-production task. A time-production task was used to assess distortions in judging elapsed time (Dougherty, Mathias, Marsh, \& Jagar, 2005). Each trial requests participants to start a timer (by a key press) and to stop the timer (by pressing the key again) after a particular time interval has passed. The to-be produced target time intervals were 2 , $5,10,20,30,45$, and $60 \mathrm{~s}$. Five trials for each interval were used, leading to a total of 35 test trials (in a completely random order). The task began with four warm-up trials to allow participants familiarize with the task.

Altman Self-Rating Mania Scale (ASRM). The ASRM (Altman, Hedeker, Peterson, \& Davis, 1997) assesses the presence and severity of manic or hypomanic symptoms using five items. Items are answered on a 5-point scale ranging from 0 (symptom not present) to 4 (symptom strongly present). The total score ranges from 0 to 20 . A cut-off score of $\geq 6$ is recommended. The ASRM has been shown to have good test-retest reliability, concurrent validity, and sensitivity to change (Altman et al., 1997).

Borderline Symptom List 23 (BSL-23). The German version of the BSL (Bohus et al., 2009) is a 23-item selfreport instrument that measures borderline symptom severity on a 5-point scale ranging from 0 (not at all) to 4 (very strong). The BSL-23 demonstrated a high internal consistency (Cronbach's $\alpha=.93-.97)$, good test-retest reliability ( $r=.82$ after 1 week), ability to discriminate between patient groups, and sensitivity for change (Bohus et al., 2009).

Modified Beck Depression Inventory (M-BDI). Symptoms of depression were assessed using the 20-item German version (Schmitt \& Maes, 2000) of the M-BDI (Beck \& Steer, 1987). The M-BDI prompts respondents to indicate the frequency of experiencing symptoms of depression on a 6-point scale ranging from 0 (never) to 5 (almost always). Schmitt, Altstötter-Gleich, Hinz, Maes, and Brähler (2006) suggest a cut-off score of $\geq 35$ as indicative for clinically relevant depressive symptoms (85th percentile of a representative sample of the German population). The M-BDI showed high internal consistency (Cronbach's $\alpha=.93$ ) and good validity (Schmitt et al., 2003).

Obsessive Compulsive Inventory (OCI-R). Symptoms of obsessive-compulsive disorder were assessed using the German version (Gönner, Leonhart, \& Ecker, 2008) of the OCI-R (Foa et al., 2002). The OCI-R is an 18-item selfreport measure that comprises six subscales: washing, checking, ordering, obsessing, hoarding, and neutralizing. Respondents indicate the presence of symptoms in the past month on a 5-point scale from 0 (not at all) to 4 (extremely). The OCI-R demonstrated good reliability and convergent and divergent validity. Gönner et al. (2008) recommend a cut-off score of 17.

Pathological Buying Screener (PBS). The PBS (Müller, Trotzke, Mitchell, de Zwaan, \& Brand, 2015) assesses symptoms of PB. The PBS comprises 13 items answered on a 5-point scale ranging from 1 (never) to 5 (almost always) and two factors "loss of control/consequences" (10 items) and "excessiveness" (3 items). The PBS has been developed in German language. Evidence for reliability and validity has been provided. There are two suggested cut-off scores. A score above 28 refers to $2 S D$ above the mean in a general population sample. A score of at least 39 occurs when each problematic behavior occurs at least "sometimes" on average.

Alcohol, Smoking and Substance Involvement Screening Test (WHO-ASSIST). The WHO-ASSIST (WHO Assist Working Group, 2002) is a validated (Humeniuk et al., 2008) screening instrument assessing the risk of abuse of diverse substance groups using seven items each. In this study, eight different substance groups (alcohol, amphetamine, cannabis, cocaine, hallucinogens, inhalants, opioids, and sedatives) were assessed using the German version of the WHO-ASSIST. For each substance group, the risk score ranges from 0 (no risk) to 39 (maximum risk). A value above 3 (12 for alcohol) for each substance group indicates the need for a short-term therapy and a value above 26 indicates the need for intensive therapy. We computed the mean across all substance groups to express the severity of substance use.

UPPS Impulsive Behavior Scale (UPPS). Dispositional impulsivity was assessed using the German version (Schmidt, Gay, d'Acremont, \& Van der Linden, 2008) of the UPPS (Whiteside \& Lynam, 2001; Whiteside, Lynam, Miller, \& Reynolds, 2005). The UPPS assesses four dimensions of dispositional impulsivity: urgency (12 items), (lack of) premeditation (11 items), (lack of) perseverance (10 items), and sensation seeking (12 items). Items are answered on a 4-point scale ranging from 1 (strongly disagree) to 4 (strongly agree). The reliability and validity of the German UPPS has been confirmed (Schmidt et al., 2008).

\section{Statistical analyses}

The relation between PB symptoms and time-perception was measured using Pearson's correlations. Stepwise 
multiple regressions were used to control for the presence of symptoms of other disorders and dispositional impulsivity. The alpha-error was set to $5 \%$. The computation of the timeperception score proceeded as follows. For each participant, we first computed the median of the estimated times across the five trials for each of the seven target time intervals. We then computed the proportionate deviation for each time interval by dividing participants' median estimated time by the actual target time.

\section{Ethics}

The study procedures were carried out in accordance with the Declaration of Helsinki. The institutional review board of the University of Mannheim approved the study. All participants were informed about the study and all provided informed consent.

\section{RESULTS}

All measures exhibited good to excellent internal consistencies (Table 1). According to the guidelines by Müller, Trotzke, et al. (2015), 18\% and $8 \%$ of the sample, respectively, scored above the cut-off scores for PB (2 SD above the mean in a general population sample and each problematic behavior occurs at least "sometimes" on average, respectively). Symptoms of PB were significantly positively correlated with borderline $(r=.29)$, depression $(r=.27)$, and OCD $(r=.24)$ symptoms, but not with symptoms of mania $(r=-.06)$ and substance-use severity $(r=.09)$. In addition, PB symptoms were significantly positively related to UPPSurgency $(r=.22)$, but did not show a significant association with UPPS-premediation $(r=-.13)$, UPPS-perseverance $(r=.06)$, or UPPS-sensation seeking $(r=-.22)$.

\section{Distortions in judging elapsed time}

On average, participants quite accurately recovered the target interval and only slightly underestimated the actual time passed (i.e., responded after the target time interval) by $5.9 \%(S D=29.5)$. The deviation scores of the different target time intervals were highly correlated $(.52<r<.96$; median $r=.88$ ). Correspondingly, an exploratory factor analysis on the deviation scores suggested a single factor accounting for $82 \%$ of the variance. In light of these results suggesting no systematic differences depending on the duration of the target interval, we decided to take the mean across the standardized deviation scores as the measure of time perception. Complimentary analyses have been separately performed for each of the time intervals, provided identical results to those obtained with the average score.

The PBS was the only measure that was significantly correlated with performance in the time paradigm $(r=-.34)$, indicating that participants with more PB symptoms tended to overestimate the actual time passed (i.e., believed that the specified time interval has been passed earlier). Notably, none of the UPPS scales were significantly related to time perception. In order to evaluate whether the PBS continues to predict performance in the time-production task over and beyond the remaining variables, we regressed the time-perception score on PBS and the remaining variables using stepwise multiple regression (Table 2). In the first step, we entered the ASRM, BSL-23, M-BDI, OCI-R, and WHO-ASSIST as background variables. The model did not account for a significant proportion of the variance in time perception $\left(R^{2}=.02\right)$ and none of the predictors were significant. In the second step, we additionally included the four UPPS subscales, however, none of which were significant. In the final step, we additionally included PBS. This model explained $19 \%$ of the variance

Table 1. Means, standard deviations (SDs), and correlations (internal consistencies on the diagonal)

\begin{tabular}{|c|c|c|c|c|c|c|c|c|c|c|c|c|}
\hline Variable & Mean $(S D)$ & 1 & 2 & 3 & 4 & 5 & 6 & 7 & 8 & 9 & 10 & 11 \\
\hline 1. PBS & $23.00(7.97)$ & $(.92)$ & & & & & & & & & & \\
\hline 2. ASRM & $7.53(3.28)$ & -.06 & $(.79)$ & & & & & & & & & \\
\hline 3. BSL-23 & $12.86(14.25)$ & $.29 * *$ & .00 & $(.96)$ & & & & & & & & \\
\hline 4. M-BDI & $32.87(15.00)$ & $.27 *$ & -.01 & $.79 * *$ & $(.92)$ & & & & & & & \\
\hline 5. OCI & $32.00(11.06)$ & $.24^{*}$ & .06 & $.65 * *$ & $.62 * *$ & $(.91)$ & & & & & & \\
\hline 6. WHO-ASSIST & $1.28(1.37)$ & .09 & .11 & $.35 * *$ & $.31^{* *}$ & $.27 *$ & $(.81)$ & & & & & \\
\hline 7. UPPS: urgency & $27.24(5.48)$ & $.22 *$ & .01 & $.43 * *$ & $.53^{* *}$ & $.45^{* *}$ & $.26^{*}$ & $(.84)$ & & & & \\
\hline $\begin{array}{l}\text { 8. UPPS: (lack of) } \\
\text { premeditation }\end{array}$ & $23.23(4.16)$ & -.13 & -.14 & .06 & .05 & -.22 & $.27 *$ & .00 & $(.74)$ & & & \\
\hline $\begin{array}{l}\text { 9. UPPS: (lack of) } \\
\text { perseverance }\end{array}$ & $22.51(4.41)$ & .06 & .04 & $.30 * *$ & $.46^{* *}$ & .18 & .20 & $.37 * *$ & $.31 * *$ & $(.81)$ & & \\
\hline $\begin{array}{l}\text { 10. UPPS: sensation } \\
\text { seeking }\end{array}$ & $30.63(6.48)$ & -.22 & .13 & -.02 & -.13 & -.07 & .20 & $-.24 *$ & $.33 * *$ & -.11 & $(.82)$ & \\
\hline 11. Time production & $1.06(0.30)^{\mathrm{a}}$ & $-.34 * *$ & -.10 & -.04 & -.09 & -.01 & .00 & .05 & .18 & -.06 & .09 & $(.97)$ \\
\hline
\end{tabular}

Note. Correlations (off-diagonal) and Cronbach's $\alpha$ estimates of internal consistencies (diagonal). PBS: Pathological Buying Screener; ASRM: Altman Self-Rating Mania Scale; BSL-23: Borderline Symptom Checklist; M-BDI: Modified Beck Depression Inventory; OCI: Obsessive Compulsive Disorder Inventory; WHO-ASSIST: Alcohol, Smoking and Substance Involvement Screening Test; UPPS: UPPS Impulsive Behavior Scale; Time production: performance in the time-production task.

${ }^{a}$ Proportionate deviation score for the time-production task, defined as the estimated time divided by the target time.

$* p<.05 .{ }^{* *} p<.01$. 
Table 2. Stepwise multiple regression predicting time perception

\begin{tabular}{|c|c|c|c|c|c|c|}
\hline Variable & $\beta$ & $t$ & $p$ & $\Delta R^{2}$ & $F$ & $p$ \\
\hline Step 1 & & & & .02 & 0.34 & .89 \\
\hline ASRM & 0.00 & -0.90 & .37 & & & \\
\hline BSL-23 & -0.11 & 0.22 & .83 & & & \\
\hline M-BDI & 0.04 & -0.89 & .37 & & & \\
\hline OCI & -0.17 & 0.39 & .70 & & & \\
\hline WHO-ASSIST & 0.06 & 0.28 & .78 & & & \\
\hline Step 2 & & & & .05 & 1.11 & .36 \\
\hline UPPS: urgency & 0.15 & 1.03 & .31 & & & \\
\hline UPPS: lack of premeditation & 0.23 & 1.46 & .15 & & & \\
\hline UPPS: lack of perseverance & -0.13 & -0.85 & .40 & & & \\
\hline UPPS: sensation seeking & 0.05 & 0.37 & .72 & & & \\
\hline Step 3 & & & & .11 & 9.04 & $<.01$ \\
\hline PBS & -0.36 & -3.00 & $<.01$ & & & \\
\hline Total $R^{2}$ & & & & .19 & 1.54 & .14 \\
\hline
\end{tabular}

Note. Standardized regression coefficients $(\beta)$ with $t$-tests and $p$ values and increase in the proportion of variance explained $\left(\Delta R^{2}\right)$ with $F$-tests and $p$ values. PBS: Pathological Buying Screener; ASRM: Altman Self-Rating Mania Scale; BSL-23: Borderline Symptom Checklist; M-BDI: Modified Beck Depression Inventory; OCI: Obsessive Compulsive Disorder Inventory; WHO-ASSIST: Alcohol, Smoking and Substance Involvement Screening Test; UPPS: UPPS Impulsive Behavior Scale.

in time distortions, with the PBS score being the only significant predictor variable $(\beta=-0.36, p<.01)$.

\section{DISCUSSION AND CONCLUSIONS}

The aim of this study was to investigate whether PB propensity is associated with distortions in judging in elapsed time. In line with our hypothesis, a higher PB propensity was associated with increased distortions of judging elapsed time, such that individuals with high levels of PB showed the tendency to believe that time elapses more slowly. The association between PB symptoms and time distortions was virtually unaffected when symptoms of related disorders and general trait impulsivity were controlled for. This indicates that distorted time perceptions are genuinely associated with PB propensity, rather than being due to symptoms of related disorders or elevated trait impulsivity. It is further interesting to note that none of the UPPS scales assessing dispositional impulsivity was significantly related to time perception. This is in line with previous findings indicating that behavioral and self-report measures tap different aspects of impulsivity (Cyders \& Coskunpinar, 2011; Stahl et al., 2014). Consequently, it seems mandatory to consider both laboratory tasks and questionnaire measures to identify specific deficits in impulse control.

In sum, the results suggests that PB propensity is not only associated with an underestimation of the actual duration of buying episodes (McElroy et al., 1994), but also with general, non-specific deficits in judging elapsed time, thereby confirming the notion that dysfunctions in impulse control belong to the symptomatology of PB. This study thereby extends to previous research linking $\mathrm{PB}$ with deficits in the response inhibition (Derbyshire et al., 2014; Hague et al., 2016; Nicolai et al., 2016), stimulus interference (Büttner et al., 2014; Starcke et al., 2012; Trotzke et al., 2014), and delay discounting (Nicolai \& Moshagen, 2017) components of behavioral impulsivity by adding distortions in judging elapsed time to this list. However, it should be remembered that behavioral impulsivity must be considered as a multifaceted construct, so it is well possible that other components of behavioral impulsivity (such as proactive interference or information sampling) are not adversely affected. More generally, we also want to highlight the importance to distinguish particular classes of cognitive processes when studying possible deficits in executive functioning in PB. For example, the heterogeneous results that are obtained concerning decision-making of individuals with PB (Black et al., 2012; Derbyshire et al., 2014; Trotzke et al., 2014, 2015; Voth et al., 2014) might be explained by the fact that the tasks employed in previous studies involve different processes (Trotzke, Brand, \& Starcke, 2017). Relatedly, numerous different processes are involved in executive functioning, so it is hardly surprising that results are mixed concerning possible deficits in executive functioning (e.g., Black et al., 2012; Derbyshire et al., 2014; Trotzke et al., 2015).

Several limitations of this study should be noted. Most importantly, the study is based on a non-clinical sample. While most researchers conceive $\mathrm{PB}$ as a dimensional phenomenon with normal variations (e.g., Billieux et al., 2008; Dittmar, 2004; Raab, Neuner, Reisch, \& Scherhorn, 2005; Vogt et al., 2015; Workman \& Paper, 2010), so that analogue samples are well suited to gain insights into the mechanisms that distinguish absence of problems or subclinical from clinical states; future studies should generalize these findings by comparing clinically impaired pathological buyers with healthy controls. In addition, a number of potentially relevant variables such as behavioral addictions or impulse control disorders were not assessed. The results concerning the ASRM should be treated with caution, because the German version has not undergone validation (however, see Bräunig, Sarkar, Effenberger, Schoofs, \& Krüger, 2009 for applications of the German ASRM). Finally, the time intervals used in the time-production task 
varied in the suprasecond interval (from 1 to $60 \mathrm{~s}$ ), therefore it is not possible to state whether the observed deficit in judging elapsed time also occurs for very brief $(<1 \mathrm{~s})$ or longer time intervals.

In conclusion, this study indicates that PB propensity is associated with distortions in judging elapsed time, such that time is perceived to pass more slowly. This result holds when controlling for symptoms of related mental disorders and general dispositional impulsivity. As such, this study adds to the growing body of research relating PB with deficits in behavioral impulsivity by suggesting that these dysfunctions also affect judgments of elapsed time.

Funding sources: No financial support was received for this study.

Authors' contribution: JN and MM designed the study, managed data collection, performed data analysis, and interpretation. All authors had full access to the data and take full responsibility for the integrity of the data and the accuracy of the data analysis. JN wrote the first draft of the manuscript. All authors approved the final version of the manuscript.

Conflict of interest: The authors declare no conflict of interest.

\section{REFERENCES}

Altman, E. G., Hedeker, D., Peterson, J. L., \& Davis, J. M. (1997). The Altman Self-Rating Mania Scale. Biological Psychiatry, 42(10), 948-955. doi:10.1016/S0006-3223(96)00548-3

Barratt, E. S. (1983). The biological basis of impulsiveness: The significance of timing and rhythm disorders. Personality and Individual Differences, 4(4), 387-391. doi:10.1016/0191-8869 (83)90004-1

Beck, A. T., \& Steer, R. A. (1987). Beck Depression Inventory (BDI). San Antonio, TX: The Psychological Corporation Inc.

Berlin, H. A., \& Rolls, E. T. (2004). Time perception, impulsivity, emotionality, and personality in self-harming borderline personality disorder patients. Journal of Personality Disorders, 18(4), 358-378. doi:10.1521/pedi.2004.18.4.358

Billieux, J., Rochat, L., Rebetez, M. M. L., \& Van der Linden, M. (2008). Are all facets of impulsivity related to self-reported compulsive buying behavior? Personality and Individual Differences, 44(6), 1432-1442. doi:10.1016/j.paid.2007.12.011

Black, D. W., Shaw, M., McCormick, B., Bayless, J. D., \& Allen, J. (2012). Neuropsychological performance, impulsivity, ADHD symptoms, and novelty seeking in compulsive buying disorder. Psychiatry Research, 200(2-3), 581-587. doi:10.1016/j. psychres.2012.06.003

Bohus, M., Kleindienst, N., Limberger, M. F., Stieglitz, R.-D., Domsalla, M., Chapman, A. L., Steil, R., Philipsen, A., \& Wolf, M. (2009). The short version of the Borderline Symptom List (BSL-23): Development and initial data on psychometric properties. Psychopathology, 42(1), 32-39. doi:10.1159/ 000173701
Bräunig, P., Sarkar, R., Effenberger, S., Schoofs, N., \& Krüger, S. (2009). Gender differences in psychotic bipolar mania. Gender Medicine, 6(2), 356-361. doi:10.1016/j.genm.2009.07.004

Büttner, O. B., Florack, A., Leder, H., Paul, M. A., Serfas, B. G., \& Schulz, A. M. (2014). Hard to ignore: Impulsive buyers show an attentional bias in shopping situations. Social Psychological and Personality Science, 5(3), 343-351. doi:10.1177/ 1948550613494024

Christenson, G. A., Faber, R. J., de Zwaan, M., Raymond, N. C., Specker, S. M., Ekern, M. D., Mackenzie, T. B., Crosby, R. D., Crow, S. J., \& Eckert, E. D. (1994). Compulsive buying: Descriptive characteristics and psychiatric comorbidity. Journal of Clinical Psychiatry, 55, 5-11.

Claes, L., \& Müller, A. (2017). Resisting temptation: Is compulsive buying an expression of personality deficits? Current Addiction Reports, 4(3), 237-245. doi:10.1007/s40429-017-0152-0

Cyders, M. A. (2015). The misnomer of impulsivity: Commentary on "choice impulsivity" and "rapid-response impulsivity" articles by Hamilton and colleagues. Personality Disorders, 6(2), 204-205. doi:10.1037/per0000123

Cyders, M. A., \& Coskunpinar, A. (2011). Measurement of constructs using self-report and behavioral lab tasks: Is there overlap in nomothetic span and construct representation for impulsivity? Clinical Psychology Review, 31(6), 965-982. doi:10.1016/j.cpr.2011.06.001

Danckert, J. A., \& Allman, A.-A. A. (2005). Time flies when you're having fun: Temporal estimation and the experience of boredom. Brain and Cognition, 59(3), 236-245. doi:10.1016/j. bandc.2005.07.002

Derbyshire, K. L., Chamberlain, S. R., Odlaug, B. L., Schreiber, L. R., \& Grant, J. E. (2014). Neurocognitive functioning in compulsive buying disorder. Annals of Clinical Psychiatry, 26(1), 57-63.

Dittmar, H. (2004). Understanding and diagnosing compulsive buying. In R. H. Coombs (Ed.), Handbook of addictive disorders: A practical guide to diagnosis and treatment (pp. 411-450). New York, NY: Wiley.

Dougherty, D. M., Mathias, C. W., Marsh, D. M., \& Jagar, A. A. (2005). Laboratory behavioral measures of impulsivity. Behavior Research Methods, 37(1), 82-90. doi:10.3758/ BF03206401

Foa, E. B., Huppert, J. D., Leiberg, S., Langner, R., Kichic, R., Hajcak, G., \& Salkovskis, P. M. (2002). The ObsessiveCompulsive Inventory: Development and validation of a short version. Psychological Assessment, 14(4), 485-496. doi:10.1037/1040-3590.14.4.485

Goldberg, Y. K., Eastwood, J. D., LaGuardia, J., \& Danckert, J. (2011). Boredom: An emotional experience distinct from apathy, anhedonia, or depression. Journal of Social and Clinical Psychology, 30(6), 647-666. doi:10.1521/jscp.2011. 30.6.647

Gönner, S., Leonhart, R., \& Ecker, W. (2008). The ObsessiveCompulsive Inventory-Revised (OCI-R): Validation of the German version in a sample of patients with OCD, anxiety disorders, and depressive disorders. Journal of Anxiety Disorders, 22(4), 734-749. doi:10.1016/j.janxdis.2007.07.007

Hague, B., Kellett, S., \& Sheeran, P. (2016). Testing the generalizability of impulse control problems in compulsive buying. Journal of Social and Clinical Psychology, 35(4), 269-288. doi:10.1521/jscp.2016.35.4.269 
Humeniuk, R., Ali, R., Babor, T. F., Farrell, M., Formigoni, M. L., Jittiwutikarn, J., de Lacerda, R. B., Ling, W., Marsden, J., Monteiro, M., Nhiwatiwa, S., Pal, H., Poznyak, V., \& Simon, S. (2008). Validation of the Alcohol, Smoking and Substance Involvement Screening Test (ASSIST). Addiction, 103(6), 1039-1047. doi:10.1111/j.1360-0443.2007.02114.x

Lawrence, J. B., \& Stanford, M. S. (1998). Impulsivity and time of day: Effects on performance and cognitive tempo. Personality and Individual Differences, 26(2), 199-207. doi:10.1016/ S0191-8869(98)00022-1

Lejoyeux, M., Tassain, V., \& Adès, J. (1997). Study of compulsive buying in depressed patients. Journal of Clinical Psychiatry, 58(4), 169-173. doi:10.4088/JCP.v58n0406

Maraz, A., Griffiths, M. D., \& Demetrovics, Z. (2016). The prevalence of compulsive buying: A systematic review and metaanalysis. Addiction, 111(3), 408-419. doi:10.1111/add.13223

McElroy, S. L., Keck, P. E., Pope, H. G., Smith, J. M., \& Strakowski, S. M. (1994). Compulsive buying: A report of 20 cases. The Journal of Clinical Psychiatry, 55, 242-248.

Moreira, D., Pinto, M., Almeida, F., \& Barbosa, F. (2016). Time perception deficits in impulsivity disorders: A systematic review. Aggression and Violent Behavior, 27, 87-92. doi:10.1016/j.avb.2016.03.008

Müller, A., Mitchell, J. E., \& De Zwaan, M. (2015). Compulsive buying. American Journal on Addictions, 24(2), 132-137. doi:10.1111/ajad.12111

Müller, A., Trotzke, P., Mitchell, J. E., de Zwaan, M., \& Brand, M. (2015). The pathological buying screener: Development and psychometric properties of a new screening instrument for the assessment of pathological buying symptoms. PLoS One, 10(10), e0141094. doi:10.1371/journal.pone.0141094

Nicolai, J., Darancó, S., \& Moshagen, M. (2016). Effects of mood state on impulsivity in pathological buying. Psychiatry Research, 244, 351-356. doi:10.1016/j.psychres.2016.08.009

Nicolai, J., \& Moshagen, M. (2017). Dissociating pathological buying from obsessive compulsive symptoms using delay discounting. Zeitschrift Für Psychologie, 225(3), 244-251. doi:10.1027/2151-2604/a000308

Patton, J. H., Stanford, M. S., \& Barrett, E. S. (1995). Factor structure of the Barratt Impulsiveness Scale. Journal of Clinical Psychology, 51(6), 768-774. doi:10.1002/10974679(199511)51:6<768::AID-JCLP2270510607>3.0.CO;2-1

Raab, G., Neuner, M., Reisch, L., \& Scherhorn, G. (2005). SKSKScreeningverfahren zur Erhebung von kompensatorischem und süchtigem Kaufverhalten [Screening instrument for the assessment of compensatory and addictive buying behavior]. Göttingen: Hogrefe.

Racine, E., Kahn, T., \& Hollander, E. (2014). Compulsive buying disorder. In K. P. Rosenberg \& L. C. Feder (Eds.), Behavioral addictions : Criteria, evidence, and treatment (pp. 285-315). New York, NY: Academic Press.

Reynolds, B., Ortengren, A., Richards, J. B., \& de Wit, H. (2006). Dimensions of impulsive behavior: Personality and behavioral measures. Personality and Individual Differences, 40(2), 305-315. doi:10.1016/j.paid.2005.03.024

Reynolds, B., \& Schiffbauer, R. (2004). Measuring state changes in human delay discounting: An experiential discounting task. Behavioural Processes, 67(3), 343-356. doi:10.1016/S03766357(04)00140-8

Rose, P., \& Segrist, D. J. (2014). Negative and positive urgency may both be risk factors for compulsive buying. Journal of
Behavioral Addictions, 3(2), 128-132. doi:10.1556/JBA.3. 2014.011

Schlosser, S., Black, D. W., Repertinger, S., \& Freet, D. (1994). Compulsive buying: Demography, phenomenology, and comorbidity in 46 subjects. General Hospital Psychiatry, 16(3), 205-212. doi:10.1016/0163-8343(94)90103-1

Schmitt, M., Altstötter-Gleich, C., Hinz, A., Maes, J., \& Brähler, E. (2006). Normwerte für das Vereinfachte Beck-DepressionsInventar (BDI-V) in der Allgemeinbevölkerung [Normative data for the simplified Beck Depression Inventory (BDI-V) in the general population]. Diagnostica, 52(2), 51-59. doi:10.1026/0012-1924.52.2.51

Schmitt, M., Beckmann, M., Dusi, D., Maes, J., Schiller, A., \& Schonauer, K. (2003). Validity of the simplified Beck Depression Inventory. Diagnostica, 49(4), 147-156. doi:10.1026// 0012-1924.49.4.147

Schmitt, M., \& Maes, J. (2000). Vorschlag zur Vereinfachung des Beck-Depressions-Inventars (BDI) [Proposal to simplify the Beck Depression Inventory (BDI)]. Diagnostica, 46(1), 38-46. doi:10.1026//0012-1924.46.1.38

Schmidt, R. E., Gay, P., d'Acremont, M., \& Van der Linden, M. (2008). A German adaptation of the UPPS Impulsive Behavior Scale: Psychometric properties and factor structure. Swiss Journal of Psychology, 67(2), 107-112. doi:10.1024/14210185.67.2.107

Sharma, L., Markon, K. E., \& Clark, L. A. (2014). Toward a theory of distinct types of "impulsive" behaviors: A meta-analysis of self-report and behavioral measures. Psychological Bulletin, 140(2), 374-408. doi:10.1037/a0034418

Skodol, A. E., Gunderson, J. G., Pfohl, B., Widiger, T. A., Livesley, W. J., \& Siever, L. J. (2002). The borderline diagnosis I: Psychopathology, comorbidity, and personality structure. Biological Psychiatry, 51(12), 936-950. doi:10.1016/ S0006-3223(02)01324-0

Sommers, J., \& Vodanovich, S. J. (2000). Boredom proneness: Its relationship to psychological-and physical-health symptoms. Journal of Clinical Psychology, 56(1), 149-155. doi:10.1002/ (SICI)1097-4679(200001)56:1<149::AID-JCLP14>3.0.CO;2-Y

Stahl, C., Voss, A., Schmitz, F., Nuszbaum, M., Tüscher, O., Lieb, K., \& Klauer, K. C. (2014). Behavioral components of impulsivity. Journal of Experimental Psychology: General, 143(2), 850-886. doi:10.1037/a0033981

Starcke, K., Schlereth, B., Domass, D., Schöler, T., \& Brand, M. (2012). Cue reactivity towards shopping cues in female participants. Journal of Behavioral Addictions, 2(1), 17-22. doi:10.1556/JBA.1.2012.012

Trotzke, P., Brand, M., \& Starcke, K. (2017). Cue-reactivity, craving, and decision making in buying disorder: A review of the current knowledge and future directions. Current Addiction Reports, 4(3), 246-253. doi:10.1007/s40429-017-0155-x

Trotzke, P., Starcke, K., Pedersen, A., \& Brand, M. (2014). Cue-induced craving in pathological buying: Empirical evidence and clinical implications. Psychosomatic Medicine, 76(9), 694-700. doi:10.1097/PSY.0000000000000126

Trotzke, P., Starcke, K., Pedersen, A., Müller, A., \& Brand, M. (2015). Impaired decision making under ambiguity but not under risk in individuals with pathological buying-behavioral and psychophysiological evidence. Psychiatry Research, 229(1-2), 551-558. doi:10.1016/j.psychres.2015.05.043

Vogt, S., Hunger, A., Pietrowsky, R., \& Gerlach, A. L. (2015). Impulsivity in consumers with high compulsive buying 
propensity. Journal of Obsessive-Compulsive and Related Disorders, 7, 54-64. doi:10.1016/j.jocrd.2015.10.002

Voth, E. M., Claes, L., Georgiadou, E., Selle, J., Trotzke, P., Brand, M., de Zwaan, M., \& Müller, A. (2014). Reactive and regulative temperament in patients with compulsive buying and non-clinical controls measured by self-report and performance-based tasks. Comprehensive Psychiatry, 55(7), 1505-1512. doi:10.1016/j.comppsych.2014.05.011

Whiteside, S. P., \& Lynam, D. R. (2001). The five factor model and impulsivity: Using a structural model of personality to understand impulsivity. Personality and Individual Differences, 30(4), 669-689. doi:10.1016/S0191-8869(00)00064-7

Whiteside, S. P., Lynam, D. R., Miller, J. D., \& Reynolds, S. K. (2005). Validation of the UPPS Impulsive Behaviour Scale: A four-factor model of impulsivity. European Journal of Personality, 19(7), 559-574. doi:10.1002/per.556

WHO Assist Working Group. (2002). The Alcohol, Smoking and Substance Involvement Screening Test (ASSIST): Development, reliability and feasibility. Addiction, 97(9), 1183-1194. doi:10.1046/j.1360-0443.2002.00185.x

Williams, A. D., \& Grisham, J. R. (2012). Impulsivity, emotion regulation, and mindful attentional focus in compulsive buying. Cognitive Therapy and Research, 36(5), 451-457. doi:10.1007/s10608-011-9384-9

Wittmann, M., Leland, D. S., Churan, J., \& Paulus, M. P. (2007). Impaired time perception and motor timing in stimulantdependent subjects. Drug and Alcohol Dependence, 90(2-3), 183-192. doi:10.1016/j.drugalcdep.2007.03.005

Wittmann, M., \& Paulus, M. P. (2008). Decision making, impulsivity and time perception. Trends in Cognitive Sciences, 12(1), 7-12. doi:10.1016/j.tics.2007.10.004

Wittmann, M., Simmons, A. N., Flagan, T., Lane, S. D., Wackermann, J., \& Paulus, M. P. (2011). Neural substrates of time perception and impulsivity. Brain Research, 1406, 43-58. doi:10.1016/j.brainres.2011.06.048

Workman, L., \& Paper, D. (2010). Compulsive buying: A theoretical framework. Journal of Business Inquiry, 9, 89-126.

Zakay, D. (2014). Psychological time as information: The case of boredom. Frontiers in Psychology, 5, 917. doi:10.3389/ fpsyg.2014.00917

Zander, H., Claes, L., Voth, E. M., de Zwaan, M., \& Müller, A. (2016). Impulsive behaviors in patients with pathological buying. Journal of Behavioral Addictions, 5(3), 457-464. doi:10.1556/2006.5.2016.050 